\title{
Aberrant proteins expressed in skin fibroblasts of Parkinson's disease patients carrying heterozygous variants of glucocerebrosidase and parkin genes
}

\author{
PHANNEE SAWANGAREETRAKUL ${ }^{1 *}$, LUKANA NGIWSARA $^{1 *}$, VORARATT CHAMPATTANACHAI $^{1}$, \\ DARANEE CHOKCHAICHAMNANKIT ${ }^{1}$, KITTIRAT SAHARAT ${ }^{1}$, JAMES R. KETUDAT CAIRNS ${ }^{1,2}$, \\ CHANTRAGAN SRISOMSAP ${ }^{1}$, KAWINTHRA KHWANRAJ ${ }^{3}$, PERMPHAN DHARMASAROJA ${ }^{3}$, \\ TEERATORN PULKES ${ }^{4}$ and JISNUSON SVASTI ${ }^{1}$ \\ ${ }^{1}$ Laboratory of Biochemistry, Chulabhorn Research Institute, Laksi, Bangkok 10210; \\ ${ }^{2}$ School of Chemistry, Institute of Science, Suranaree University of Technology, Nakhon Ratchasima 30000; \\ ${ }^{3}$ Faculty of Science; ${ }^{4}$ Division of Neurology, Department of Medicine, Faculty of Medicine, Ramathibodi Hospital, \\ Mahidol University, Bangkok 10400, Thailand
}

Received August 21, 2020; Accepted January 21, 2021

DOI: $10.3892 / b r .2021 .1412$

\begin{abstract}
Parkinson's disease (PD) is a neurodegenerative disorder that affects movement, and its development is associated with environmental and genetic factors. Genetic variants in $G B A$ and $P A R K 2$ are important risk factors implicated in the development of PD; however, their precise roles have yet to be elucidated. The present study aimed to identify and analyse proteins from the skin fibroblasts of patients with PD carrying heterozygous $G B A$ and $P A R K 2$ variants, and from healthy controls. Liquid chromatography coupled with tandem mass spectrometry and label-free quantitative proteomics were performed to identify and compare differential protein expression levels. Moreover, protein-protein interaction networks were assessed using Search Tool for Retrieval of Interacting Genes analysis. Using these proteomic approaches, 122 and 119 differentially expressed proteins from skin fibroblasts of patients with PD carrying heterozygous $G B A$ and $P A R K 2$ variants, respectively, were identified and compared. According to the results of protein-protein interaction and Gene Ontology analyses, 14 proteins involved in the negative regulation of macromolecules and mRNA metabolic processes, and protein targeting to the membrane exhibited the largest degree of differential expression in the fibroblasts of patients with PD with a $G B A$ variant, whereas 20 proteins involved in the regulation
\end{abstract}

Correspondence to: Dr Voraratt Champattanachai, Laboratory of Biochemistry, Chulabhorn Research Institute, 54 Kamphaeng Phet 6, Talat Bang Khen, Laksi, Bangkok 10210, Thailand

E-mail: voraratt@cri.or.th

*Contributed equally

Key words: annexin A2, glucocerebrosidase, parkin, Parkinson's disease, tubulin $\beta$ chain, proteomics of biological quality, NAD metabolic process and cytoskeletal organization exhibited the largest degree of differential expression in the fibroblasts of patients with PD with a PARK2 variant. Among these, the expression levels of annexin A2 and tubulin $\beta$ chain, were most strongly upregulated in the fibroblasts of patients with GBA-PD and PARK2-PD, respectively. Other predominantly expressed proteins were confirmed by western blotting, and the results were consistent with those of the quantitative proteomic analysis. Collectively, the results of the present study demonstrated that the proteomic patterns of fibroblasts of patients with PD carrying heterozygous $G B A$ and $P A R K 2$ variants are different and unique. Aberrant expression of the proteins affected by these variants may reflect physiological changes that also occur in neurons, resulting in PD development and progression.

\section{Introduction}

Parkinson's disease (PD) is one of the most common neurodegenerative disorders of movement in the aged populations worldwide. PD is characterized pathologically by the loss of dopaminergic neurons in the substantia nigra, which results in a reduction of dopamine, a vital neurotransmitter affecting movement and balance. Whilst the exact cause of PD is generally unknown, the development and progression of the disease is considered to be associated with environmental and genetic factors (1). In total, $\sim 15 \%$ of patients have a family history of $\mathrm{PD}$, and $5-10 \%$ of cases are caused by pathogenic mutations in single genes with monogenic Mendelian inheritance (2). Mutations in numerous genes, including SNCA, PARK2 (coding for parkin), DJ-1, PINK1, LRRK2 and VPS35, are directly linked to PD, whereas variants in other genes, such as $G B A$, have been shown to be strong risk factors for PD (3). Although extensive research has focused on pathogenic gene mutations or variants, it is not fully understood how those genetic changes cause PD or influence the risk of developing this disorder in the elderly population $(4,5)$. 
Parkin is an E3 ubiquitin ligase that serves a critical role in targeting proteins for degradation. It is also involved in the clearance of damaged mitochondria via autophagy and proteasomal mechanisms. Parkin is encoded by the PARK2 (PRKN) gene, which is located on chromosome 6q25.2-q27, and spans $>500 \mathrm{~kb}$. It contains 12 exons, which translate to a protein of 465 amino acids (6). PARK2 variants appear to be responsible for PD pathogenesis, which was first reported in Japanese families in 1998 (6). According to the Human Gene Mutation Database, $>300$ pathogenic mutations have been identified in the PARK2 gene (hgmd.cf.ac.uk/ac/gene.php?gene=PRKN; accessed July 2020), most of which are gross deletions, followed by missense mutations, gross insertions, small deletions, splicing defects and small insertions. Although the mechanism by which loss of parkin function results in dopaminergic cell death in PD is unclear, it is considered to involve the disruption of mitochondrial quality control (7).

Glucocerebrosidase(GCase;EnzymeCommission 3.2.1.45), also known as acid- $\beta$ glucosidase (GBA) and glucosylceramidase, is a lysosomal enzyme that is responsible for the hydrolysis of glucocerebroside, an intermediate in the glycolipid metabolism and an abundant sphingolipid present in the plasma membranes. It is encoded by the GBA gene, which is located on chromosome 1q21, spans $\sim 7.6 \mathrm{~kb}$ and contains 11 exons. Mutations in the GBA gene cause Gaucher's disease (GD), an autosomal recessive lysosomal storage disease that is characterized by the accumulation of glucocerebrosides in macrophages referred to as 'Gaucher cells'. There are three clinical subtypes of GD that have been recognized: Type 1 is non-neuronopathic, whereas types 2 and 3 are acute and chronic neuronopathic, respectively. Based on the Human Gene Mutation Database, $>400$ mutations have been reported in the $G B A$ gene (hgmd.cf.ac.uk/ac/gene.php?gene=GBA; accessed July 2020). The majority of these mutations are missense, followed by small deletions, splicing defects, complex rearrangements and small insertions. Of note, a highly homologous pseudogene $(G B A P)$ is located $\sim 16 \mathrm{~kb}$ downstream from the $G B A$ gene and shares $96 \%$ sequence identity to the functional $G B A$ gene (8). The presence of this pseudogene at the same locus causes recombination events between the $G B A$ and $G B A P$ genes, thus resulting in several different mutations in GD $(9,10)$.

Several lines of evidence suggest that $G B A$ homozygous or heterozygous variants are associated with an increased risk of developing PD. A study on brain samples from 57 subjects clinically diagnosed with PD demonstrated that $G B A$ variants were present in 12 cases $(21 \%)$, and these were more frequent amongst younger subjects (11). Another study on blood samples from 99 Ashkenazi Jewish patients with PD showed that $6 G B A$ variants were identified in 31 cases $(31 \%)$, and that patients carrying the $G B A$ variants were younger than those who were not carriers (12). Furthermore, a multicentre analysis from 16 centres reported that, amongst the $G B A$ variants of $>5,000$ patients with $\mathrm{PD}, 2$ known $G B A$ variants, L444P and N370S, were commonly associated with PD in all ethnic groups (13). However, each population also had unique variants $(10,12,14,15)$. In Thailand, heterozygous $G B A$ variants were reported in 24 out of 480 patients with PD (5\%), including L444P (c.1448T>C), IVS10-9_10GT>AG, P428S (c.1399C>T), N386K (c.1275C>A), V398fsX404 (c.1309delG), IVS2+1G>A and IVS9+3G $>C$ (10). Previous studies on various populations suggested that $5-10 \%$ of patients with PD had $G B A$ variants, although the percentage was much greater in the Ashkenazi population, whereas the frequency of GBA variants in the control (non-PD) population was as low as $0.5 \%(10,16)$.

Proteomics is a large-scale study of proteins expressed in cells, mostly detected using a mass spectrometer. Proteomic findings have been widely used to identify and quantify proteins involved in the research of drug treatments, biomarkers and diseases, including PD. For example, a previous study reported a proteomic approach using 2D gel electrophoresis and tandem mass spectrometry (MS/MS) to explore the protein expression pattern in primary skin fibroblasts of patients with PD (17). Another study used non-gel based proteomics analysis to investigate proteomes in the cerebrospinal fluid of patients with PD (18). Furthermore, proteomics analysis has been applied for primary screening and detection of individuals with neurodegenerative diseases, and for distinguishing PD from other neurodegenerative diseases (19). Proteomics, therefore, is a powerful technique for identification and quantification of proteins, as well as for protein profiling and identification of biomarkers of diseases.

Primary skin fibroblasts reflect genetic changes in patients, and are useful models to study PD (20). Previously, skin fibroblasts from patients with PD with heterozygous $G B A$ and $P A R K 2$ variants, as well as from healthy controls were analysed, and it was observed that the GBA-PD group showed slightly lower activities of the complexes II, IV and V of the mitochondrial respiratory chain than the PARK2-PD group (21). The present study investigated the GCase activity in primary skin fibroblasts of 4 patients with PD, including two heterozygous $G B A$ variants and two heterozygous PARK2 variants, and this was compared with 4 heathy controls. MS and label-free quantitative proteomic analysis were performed to identify potential target proteins associated with the disease.

\section{Materials and methods}

Patients and participants. Clinical samples, including primary skin fibroblasts and peripheral blood samples, were used in this study. Primary skin fibroblasts were obtained from 4 patients with PD (median age, 46 years; age range, 41-57 years) and 4 healthy age-matched controls (median age, 45.5 years; age range, 45-53 years). These included two patients with PD carrying different heterozygous $G B A$ variants, including c.1309delG and IVS2+1G $>$ A, and two patients with PD carrying different heterozygous PARK2 variants, including c.2T $>\mathrm{C}$ and exon 8 deletion (exon8del). All participants were screened and were free of common LRRK2 mutations as well as TBP, SCNA, FBXO7 and GCH1 mutations. The age, sex, genotypic and phenotypic characterization of the investigated individuals are shown in Table I. Written informed consent was obtained from each participant, and the study protocol approved by the Institutional Review Board of Ramathibodi Hospital (Bangkok, Thailand; approval no. ID03-54-22).

Preparation and culturing of skin fibroblasts. Skin samples were obtained from the dorsal region of the inner upper arm of each participant, maintained in tubes with DMEM, stored 
at $4^{\circ} \mathrm{C}$ and processed within $4 \mathrm{~h}$. Fibroblast harvesting was performed by explant, isolating the dermis from the epidermis with scalpels and scissors. Passaged cells were cultured in DMEM containing 10\% FBS and 1\% penicillin/streptomycin. All culture media and reagents were purchased from Thermo Fisher Scientific, Inc. Skin fibroblast cultures were maintained in a humidified incubator with $95 \%$ air and $5 \% \mathrm{CO}_{2}$ at $37^{\circ} \mathrm{C}$. All experiments were performed on cells with 6-11 passages. When cell density reached $80 \%$ confluence, the cells were washed and harvested in $1 \mathrm{X}$ PBS using a cell scraper. Next, the cells were washed 2-3 times with PBS by centrifugation at $721 \mathrm{xg}$ for $10 \mathrm{~min}$ at $4^{\circ} \mathrm{C}$. The pelleted cells were stored at $-80^{\circ} \mathrm{C}$ until required for use in the enzyme activity and protein identification assays.

GCase activity assay. GCase activity was determined using a fluorometric assay with 4-methylumbelliferyl $\beta$-D-glucopyranoside (4-MU- $\beta$-Glc) as a substrate, as previously described, with certain modifications (22). All reagents were purchased from Sigma-Aldrich (Merck KGaA). After cell thawing, the fibroblasts were mixed with $200 \mu 10.9 \% \mathrm{NaCl}$ containing $1 \mathrm{mM}$ phenylmethylsulfonyl fluoride, and were homogenized with an ultrasonic homogenizer (U200H; IKA Labortechnik) at $30 \%$ amplitude and $0.2 \%$ cycle. The protein concentrations of the fibroblast lysates were measured using a Bradford protein assay (Bio-Rad Laboratories, Inc.) with BSA as a standard (Bio-Rad Protein assay standard II; cat. no. 5000007, Bio-Rad Laboratories, Inc.). For the enzyme assay, $10 \mu \mathrm{l}$ homogenized cell lysate was incubated with $90 \mu \mathrm{l}$ $5 \mathrm{mM} 4-\mathrm{MU}-\beta-$ Glc in $10 \mathrm{mM}$ sodium taurocholate at $37^{\circ} \mathrm{C}$ for $1 \mathrm{~h}$. After incubation, $200 \mu \mathrm{l} 0.5 \mathrm{M} \mathrm{NaHCO} / \mathrm{Na}_{2} \mathrm{CO}_{3}$ ( $\mathrm{pH}$ 10.7) was added to stop the reaction. The clear reaction was transferred into a 96-well microplate, and the fluorescence emission was measured using a fluorescence spectrophotometer (SpectraMax M2/M2e Multi-Mode microplate reader; Molecular Devices, LLC) with an excitation wavelength of $365 \mathrm{~nm}$ and an emission wavelength of $450 \mathrm{~nm}$. The GCase activity was calculated as the release of 4-methylumbelliferone (4-MU) per time divided by the quantity of protein used. One unit was defined as the release of $1 \mu$ mole $4-M U$ in $1 \mathrm{~h}$ per $1 \mathrm{mg}$ protein.

Sample preparation for MS. Skin fibroblasts from patients with PD with $G B A$ and $P A R K 2$ variants as well as from healthy subjects were grown in three independent passages, and all fibroblast passages were harvested as pelleted cells and stored at $-80^{\circ} \mathrm{C}$. After thawing, the packed fibroblasts were resuspended in lysis buffer containing $7 \mathrm{M}$ urea, $2 \mathrm{M}$ thiourea, 4\% CHAPS and 1X protease inhibitor cocktail (Sigma-Aldrich; Merck KGaA), and were sonicated 3-4 times at 0.3 cycle and $30 \%$ amplitude, and then incubated at $4^{\circ} \mathrm{C}$ for $30 \mathrm{~min}$. The cell debris were removed by centrifugation at $13,000 \mathrm{x} \mathrm{g}$ at $4^{\circ} \mathrm{C}$ for $10 \mathrm{~min}$. The protein concentrations of fibroblast lysates were determined using a Bradford protein assay. After protein determination, equal quantities of protein $(10 \mu \mathrm{g})$ from each cell passage were pooled, and the buffer was exchanged with $50 \mathrm{mM}$ ammonium bicarbonate using a Micro Bio-Spin Chromatography Column (Bio-Rad Laboratories, Inc).

In-solution tryptic-digestion was performed as described previously with certain modifications (23). Briefly, $10 \mu \mathrm{g}$ protein from fibroblast lysates (pooled healthy controls and individual patient samples) was reduced in $10 \mathrm{mM}$ DTT for $5 \mathrm{~min}$ at $95^{\circ} \mathrm{C}$ and alkylated with $1 / 10$ volume of $20 \mathrm{mM}$ iodoacetamide, prior to incubation for $30 \mathrm{~min}$ in the dark at room temperature. The alkylated proteins were in-solution digested overnight at $37^{\circ} \mathrm{C}$ by adding 1:50 (trypsin: protein, w/w) of sequencing-grade trypsin (Promega Corporation). The digestion reaction was stopped by adding $1 \%$ formic acid. The tryptic-digested peptides were cleaned with HiPPR ${ }^{\mathrm{TM}}$ Detergent Removal Resin (Thermo Fisher Scientific, Inc.) to remove the residual reagents, and then purified using a Ziptip $\mathrm{C}_{18}$ micropipette tip (EMD Millipore). Finally, the peptides were dried completely using a speed vacuum (Labconco) and stored at $-80^{\circ} \mathrm{C}$ for further analysis.

Liquid chromatography (LC)-MS/MS analysis. A nanoACQUITY UPLC system (Waters Corporation) coupled with an amaZon speed Ion Trap mass spectrometer (Bruker Corporation) was used to identify peptides/proteins, as described previously (23). The tryptic-digested peptides were dissolved in $0.1 \%$ formic acid in $\mathrm{H}_{2} \mathrm{O}$ and injected into a nanoACQUITY UPLC column $\left(1.7 \mu \mathrm{m} \mathrm{BEH,} 75 \mu \mathrm{m}\right.$ x $200 \mathrm{~mm} \mathrm{C}_{18}$, Water Corporation) at a flow rate of $300 \mathrm{nl} / \mathrm{min}$. The column temperature was maintained at $40^{\circ} \mathrm{C}$. The LC gradient used $0.1 \%$ formic acid in $\mathrm{H}_{2} \mathrm{O}$ as solvent $\mathrm{A}$ and $0.1 \%$ formic acid in acetonitrile as solvent $\mathrm{B}$, and was performed as follows: $1-50 \%$ solvent B for $70 \mathrm{~min}, 50-90 \%$ solvent B for $5 \mathrm{~min}$ and 15 min with $90 \%$ solvent $B$. The eluted peptides were analysed directly via MS/MS on an amaZon speed Ion Trap mass spectrometer equipped with a captive-electrospray ion source. The positive mode was used with a spray voltage of $1,300 \mathrm{~V}$, and the capillary temperature was set at $150^{\circ} \mathrm{C}$. Mass spectra were acquired from 400 to $1,400 \mathrm{~m} / \mathrm{z}$ using parameters optimized at $922 \mathrm{~m} / \mathrm{z}$ with a target of 500,000 set for ion charge control and a maximum acquisition time of $100 \mathrm{msec}$. The scan range was 50-3,000 m/z. The MS/MS data were processed using Bruker Compass version 1.4 (Bruker Corporation). Each sample was analysed in triplicate by LC-MS/MS for the normalization of the quantity of protein injected. Mascot software version 2.4.0 was used for the identification of peptides using the Swiss-Prot human protein database (Matrix Science, Ltd.). The Mascot parameters were as follows: The MS/MS mass tolerance was set at $0.6 \mathrm{Da}$; the peptide mass tolerance was set to $1.2 \mathrm{Da}$; carbamidomethylation was set as a fixed modification; and 1 missed cleavage was allowed. A false discovery rate threshold of $1 \%$ was applied.

Data analysis and label-free LC-MS quantitative profiling. Progenesis label-free LC-MS version 3.1 (Nonlinear Dynamics, Ltd.) was used to process the raw data obtained from LC-MS/MS and to compare the significant changes in protein expression levels. The method was applied to quantify peptides/proteins, as described previously, with certain modifications (23). Briefly, two sets of LC-MS/MS were performed. The first set involved nine runs with three triplicates of the two different $G B A$ variants and one pooled healthy control. The second set involved nine runs with three triplicates of the two different PARK2 variants and one pooled healthy control. The chromatograms of all the samples of each set were aligned, and the sample providing the smallest differences in 
retention times and MS peaks amongst all samples was automatically selected as the reference. The ion intensities of the MS peaks of each sample were then normalized by those of the established reference. The following criteria were used to filter all the peptide data prior to exporting the MS/MS output files, including i) only peptides presenting an ANOVA with Tukey's post-hoc test difference between the triplicate runs of $\mathrm{P}<0.05$; ii) only non-conflicted peptides (unique peptides) were used; iii) at least one run (from triplicate runs of each sample) was fragmented to generate the peptide sequences for comparison with those of other samples; and iv) at least two unique peptides with a MASCOT score of $>30(\mathrm{P}<0.05)$ were accepted for confident protein identification. The fold changes of protein expression levels were calculated from the mean values of all accepted peptides of particular proteins, and were normalized by the mean number of each protein in the healthy control group.

Heat map analysis of protein expression levels. The MS ion intensities of each protein (average peptide ion intensities) were normalized by those in the healthy control group and counted as 1.00-fold. The expression levels (normalized intensity ratio) of proteins were represented in a heat map constructed using $\mathrm{R}$ version 3.3.1 (24). The proteins were sorted by their expression levels, starting from high to low, in comparison with those of the control group. All samples were clustered with the Euclidean distance computational method and the complete agglomeration method (24).

Protein-protein interaction (PPI) analysis. STRING version 11.0 (25) was used to predict the potential PPIs of proteins affected by $G B A$ and $P A R K 2$ variants. PPI networks were constructed by mapping the top 25 proteins with the highest differential expression levels in patients with PD with $G B A$ and $P A R K 2$ variants compared with those of the healthy control group. Gene Ontology (GO) functional enrichment analysis $(26,27)$ was used to identify the biological processes in which the proteins affected by both variants are involved. The top three biological processes with the smallest false discovery rate (FDR) values were selected.

Confirmation of protein expression levels. The expression levels of certain proteins were validated by western blot analysis. These included annexin A2 (ANXA2), 60S ribosomal protein L18 (RPL18), tubulin $\beta$ chain (TUBB) and collagen $\alpha-1$ chain (COL1A1). Protein lysates of pooled fibroblasts from healthy controls and patients with PD carrying $G B A$ and $P A R K 2$ variants were resuspended in the same lysis buffer, as previously described in the sample preparation for MS. Equal protein quantities $(10 \mu \mathrm{g})$ from four pooled healthy controls and individual patient samples were separated by $10 \%$ SDS-PAGE and then transferred to $0.20-\mu \mathrm{m}$ PVDF (Pall Life Sciences). The membranes were blocked with 3\% (w/v) BSA in TBST [50 mM Tris, pH 8.0, $150 \mathrm{mM}$ $\mathrm{NaCl}$ and $0.1 \%$ Tween-20 (v/v)] for $1 \mathrm{~h}$. Next, the membranes were incubated at $4^{\circ} \mathrm{C}$ overnight in $3 \%$ BSA/TBST with the following antibodies: Anti-ANXA2 (cat. no. ab54771; Abcam; 1:1,000), anti-RPL18 (cat. no. ab241988; Abcam; 1:2,000), anti-TUBB (cat. no. 2128; Cell Signaling Technology, Inc.; 1:1,000), anti-COL1A1 (cat. no. ab138492; Abcam; 1:1,000) or anti- $\beta$-actin (cat. no. 3700; Cell Signaling Technology, Inc.; 1:20,000). After washing with TBST, the membranes were incubated with the appropriate secondary antibodies conjugated with horseradish peroxidase (cat. no. P0217, anti-rabbit and cat. no. P0260, anti-mouse; Dako, Agilent Technologies, Inc.; 1:2,000 except for anti- $\beta$-actin where 1:20,000 was used) at room temperature for $1 \mathrm{~h}$. After washing with TBST, the bands in the membranes were detected by chemiluminescence using a WesternBright ECL detection kit (Advansta, Inc.). $\beta$-actin (ACTB) was used as a protein loading control. The immunoblot signals were detected and analysed using an ImageQuant LAS 4000 mini system (GE Healthcare). Densitometry analysis was performed using ImageQuant TL 1D version 7.0 (GE Healthcare) based on the band intensity of certain proteins divided by the band intensity of the respective ACTB, and normalized to those of the pooled healthy control fibroblasts.

Statistical analysis. Protein expression is presented as the mean \pm standard deviation. Statistical differences in protein expression between the patients and healthy control groups were compared using a two-tailed unpaired t-test in Microsoft Excel ${ }^{\circledR} 2016$ (Microsoft Corporation). $\mathrm{P}<0.05$ was considered to indicate a statistically significant difference.

\section{Results}

GCase activity is decreased in patients with PD with heterozygous GBA variants. The average GCase activity level of the two patients with PD carrying heterozygous $G B A$ variants $(142 \pm 21 \mathrm{nmol} / \mathrm{h} / \mathrm{mg}$ protein) was $34 \%$ lower compared with the healthy controls $(201 \pm 36 \mathrm{nmol} / \mathrm{h} / \mathrm{mg}$ protein) and the difference was significant $(\mathrm{P}<0.05)$, whereas the patients carrying heterozygous $P A R K 2$ variants had a mean activity $(204 \pm 50 \mathrm{nmol} / \mathrm{h} / \mathrm{mg}$ protein) close to the mean value of the healthy controls (Table I).

Protein alterations in patients with PD carrying heterozygous GBA and PARK2 variants. Proteomics and label-free quantitative analysis were performed to identify proteins that may be associated with PD. For this purpose, the protein lysates of four healthy controls were pooled and compared with those of the individual variants. The first comparison set was the pool of controls (controls 1-4) and two individual samples of patients with PD carrying heterozygous $G B A$ variants; PD-GBA-1 (c.1309delG) and PD-GBA-2 (IVS2+1G>A). The second set was the pool of controls (controls 1-4) and two individual samples of patients with PD carrying heterozygous PARK2 variants; PD-PARK2-1 (c.2T>C) and PD-PARK2-2 (exon8del).

According to the criteria used to filter all MS and $\mathrm{MS} / \mathrm{MS}$ data, there were 122 proteins in the $G B A$ variants and 119 proteins in the $P A R K 2$ variants that could be compared with those found in age-matched healthy controls. Heat map analysis revealed the differential protein expression levels of fibroblasts with each $G B A$ and $P A R K 2$ variant compared with those of fibroblasts from healthy controls (Fig. 1A and B). In addition, the top 25 proteins with the highest differential expression in each variant were selected and displayed (Fig. 1C and D). Among these, the average expression of 5 and 
11 proteins in patients with PD patients with $G B A$ and $P A R K 2$ variants, respectively, was altered by $>1.5$-fold compared with that of the controls (Table IIA and B). The levels of ANXA2, histone H4, protein S100-A11 (S100A11), transgelin (TAGLN) and RPL18 were higher in the fibroblasts from patients with GBA-PD. The levels of TUBB, CD antigen 81, elongation factor 1- $\alpha$ (EEF1A1), spectrin $\alpha$ chain (SPTAN1), histone H2A type 1-B/E (HIST1H2AB), L-lactate dehydrogenase A chain (LDHA), spectrin $\beta$ chain (SPTBN1), electron transfer flavoprotein subunit $\alpha$ (ETFA), filamin-B (FLNB), polymerase I and transcript release factor (PTRF) and COL1A1 were altered in fibroblasts from patients with PARK2-PD.

PPIs between patients with PD carrying GBA and PARK2 variants. The PPIs of the top 25 proteins with differentially altered expression in skin fibroblasts of patients with PD identified by quantitative proteomic analysis were mapped by STRING analysis (Fig. 2). According to the biological processes and GO analysis, in the GBA-fibroblasts of patients with $\mathrm{PD}, 12$ proteins were involved in the negative regulation of macromolecule metabolic processes (GO:0010605, $\mathrm{FDR}=0.0143$, yellow), 7 proteins were involved in an mRNA metabolic process (GO:0016071, FDR $=0.0143$, purple) and 4 proteins acted in targeting to the membrane (GO:0006612, $\mathrm{FDR}=0.0143$, cyan) (Fig. 2A). Of note, 4 proteins categorized in GO:0010605 were upregulated by $>1.5$-fold in the GBA-fibroblasts of patients with PD (red circles in Fig. 2A). In the PARK2-fibroblasts of patients with PD, 16 proteins were involved in the regulation of biological quality (GO:0065008, $\mathrm{FDR}=0.0008$, red), 4 proteins participated in the nicotinamide adenine dinucleotide (NAD) metabolic process (GO:0019674, $\mathrm{FDR}=0.0013$, green) and 8 proteins were involved in cytoskeleton organization (GO:0007010, FDR=0.0042, blue) (Fig. 2B). Of note, 4 proteins categorized in GO:0019674, including TUBB, SPTAN1, SPTBN1 and FLNB, LDHA were categorized in GO:0019674, and another 4 proteins uncategorized in these GO biological processes, including EEF1A1, PTRF, HIST1H2AB, and ETFA, were upregulated, whereas COL1A1, categorized in GO:0065008, was downregulated, by $>1.5$-fold (red circles in Fig. 2B).

Validation of protein expression levels by western blot analysis. To validate proteins identified by label-free quantitative proteomic analysis, the levels of certain selected proteins were determined by western blotting. Specifically, four proteins, including ANXA2, RPL18, TUBB and COL1A1, whose expression levels were highly altered based on the bioinformatics analysis, were selected and analysed in pooled fibroblast samples from healthy controls and in fibroblasts from individual patients with PD carrying GBA and PARK2 variants. The levels of ANXA2 and RPL18 were upregulated, whereas COL1A1 levels were not different in fibroblasts of patients with PD carrying $G B A$ variants compared with the levels exhibited by the healthy control fibroblasts (Fig. 3A). The levels of TUBB were upregulated, while COL1A1 was downregulated and ANXA2 was not significantly differentially expressed in patients with PD carrying PARK2 variants in comparison with the levels exhibited by the healthy control fibroblasts (Fig. 3B). ACTB was used as a protein loading control (Fig. 3A and B). The expression levels of selected 

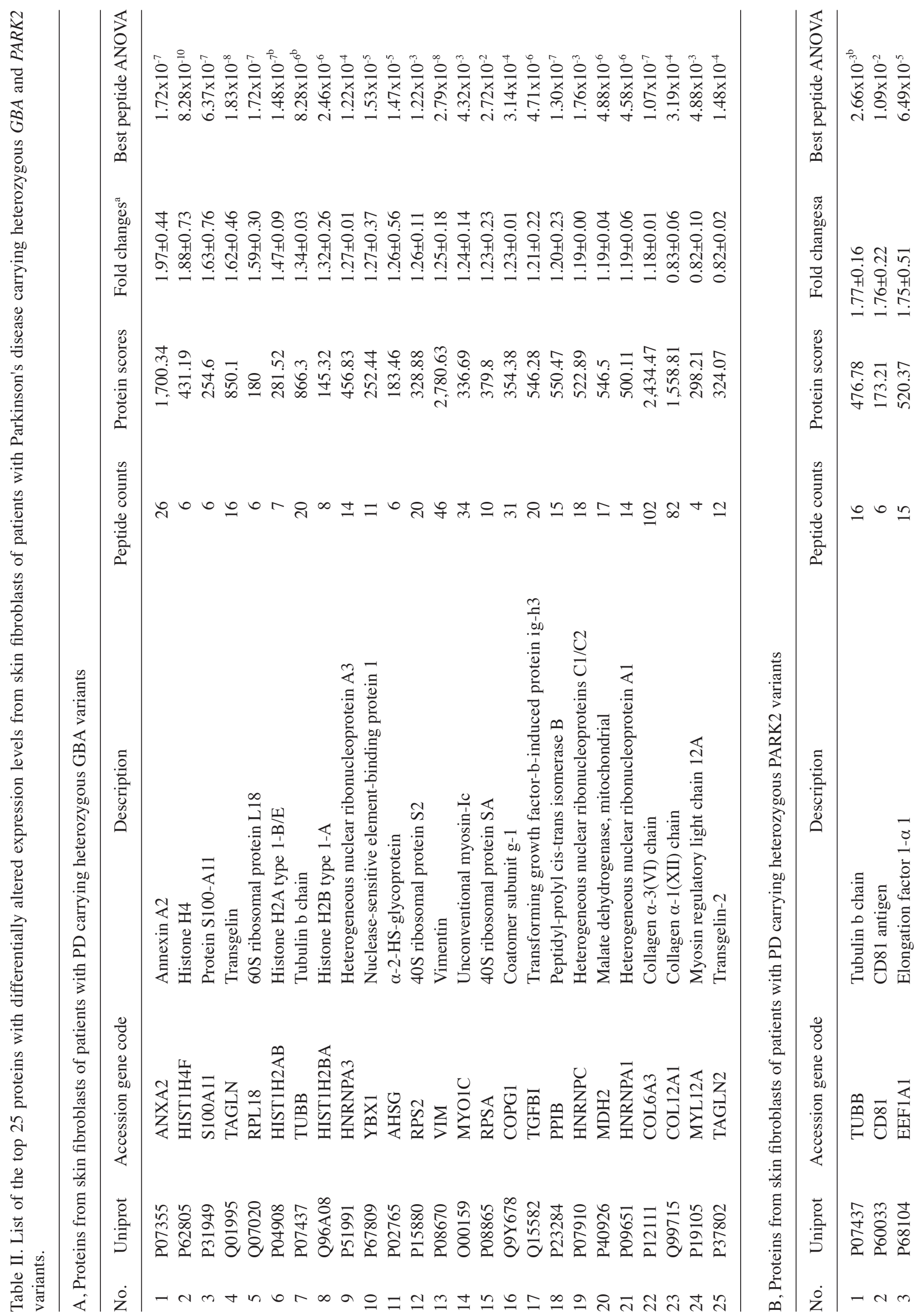


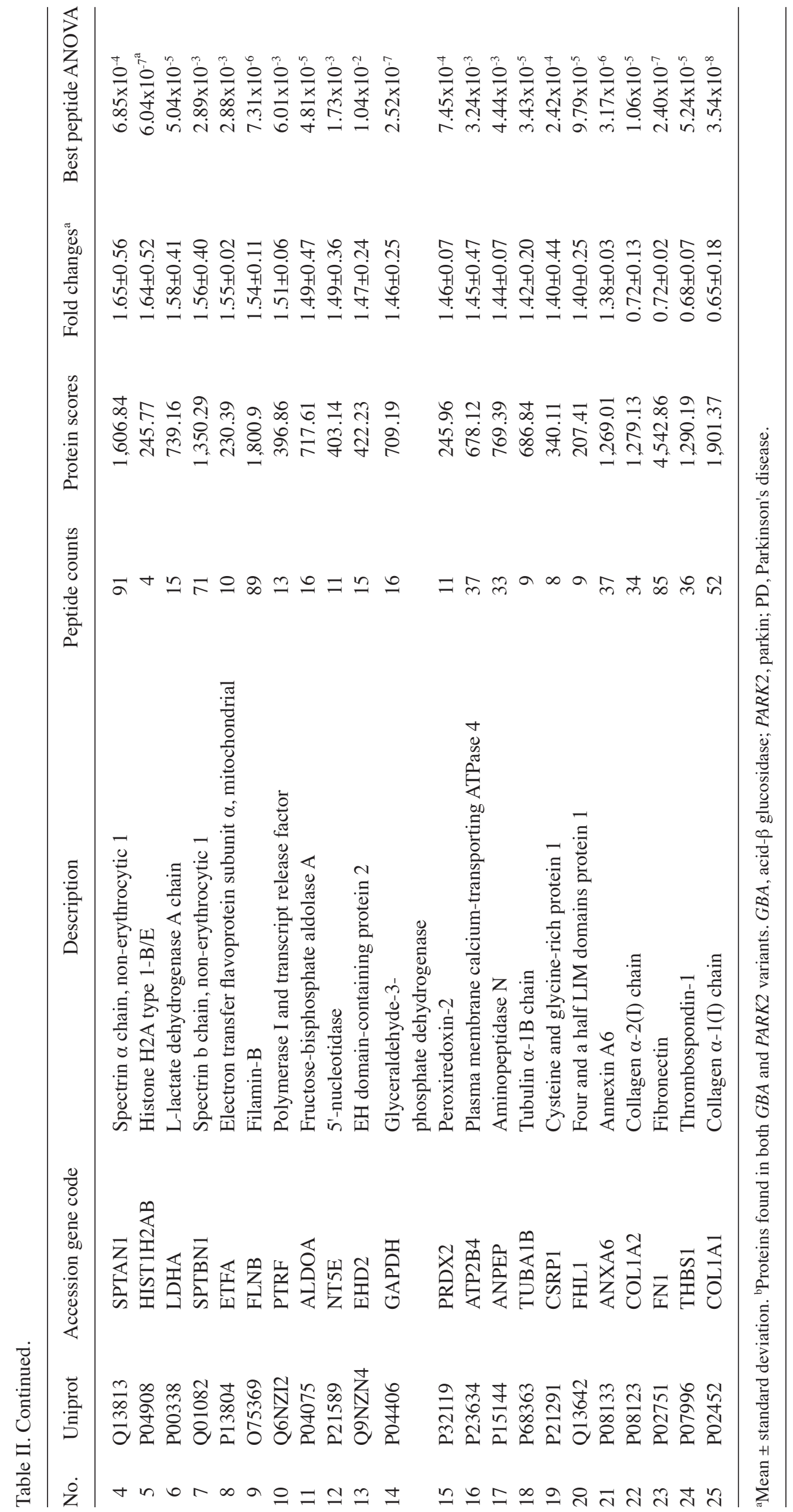


A

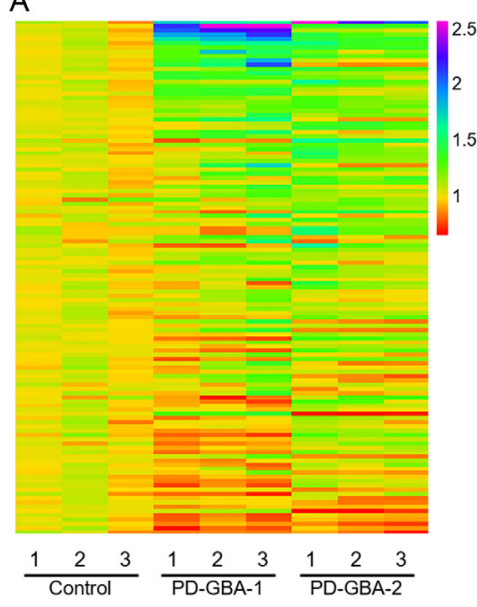

C

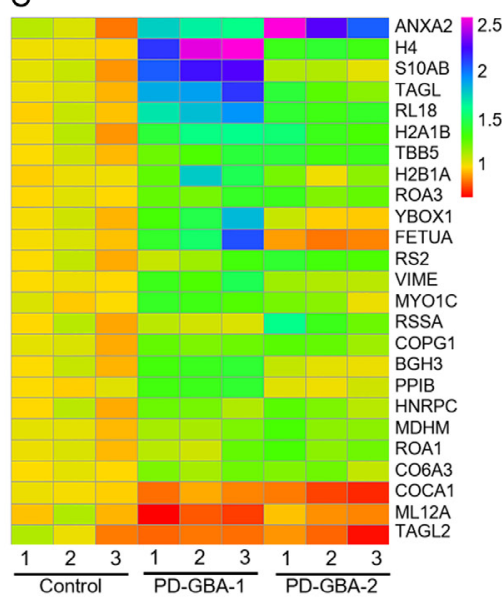

B

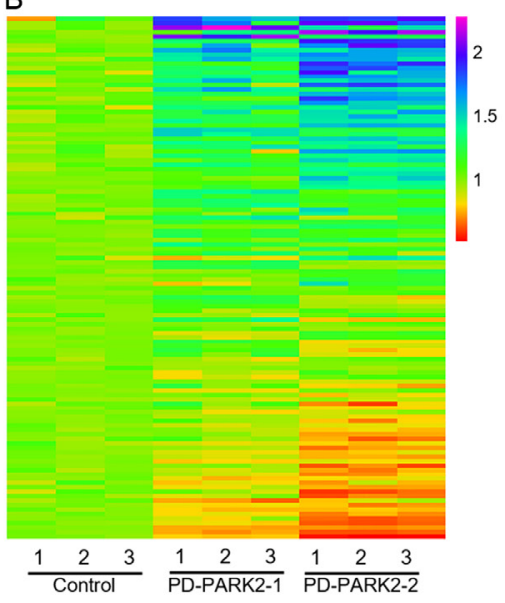

$\mathrm{D}$

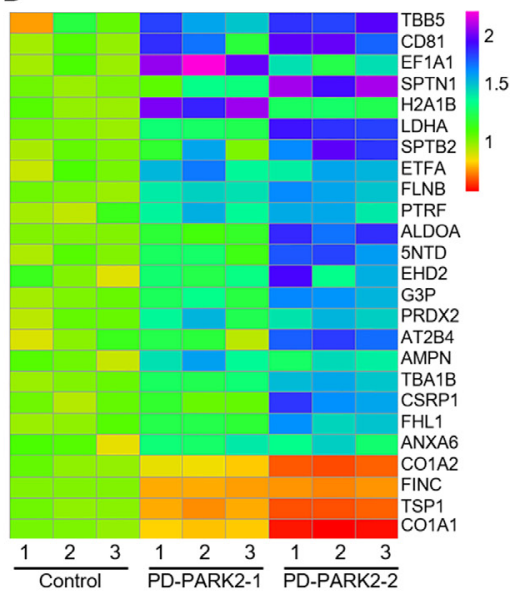

Figure 1. Heat map analysis of proteins expressed in fibroblasts of patients with PD harbouring heterozygous GBA and $P A R K 2$ variants as well as in the healthy controls. (A) Heat map of the 122 differentially expressed proteins in the fibroblasts of the two patients with PD with different heterozygous GBA variants compared with the pooled healthy controls. (B) Heat map of the 119 differentially expressed proteins in the fibroblasts of the two patients with PD with different heterozygous PARK2 variants compared with the pooled healthy controls. (C and D) Top 25 differentially expressed proteins in fibroblasts of patients with PD carrying (C) GBA and (D) PARK2 variants. Each sample was run and analysed using liquid chromatography coupled with tandem mass spectrometry. The heat map was constructed using R, and the expression levels of each protein were normalized to the mean expression level of that protein in the healthy control from triplicate runs. Abbreviated protein names correspond to the full protein names shown in Table II. PD, Parkinson's disease; GBA, acid- $\beta$ glucosidase; $P A R K 2$, parkin.

A

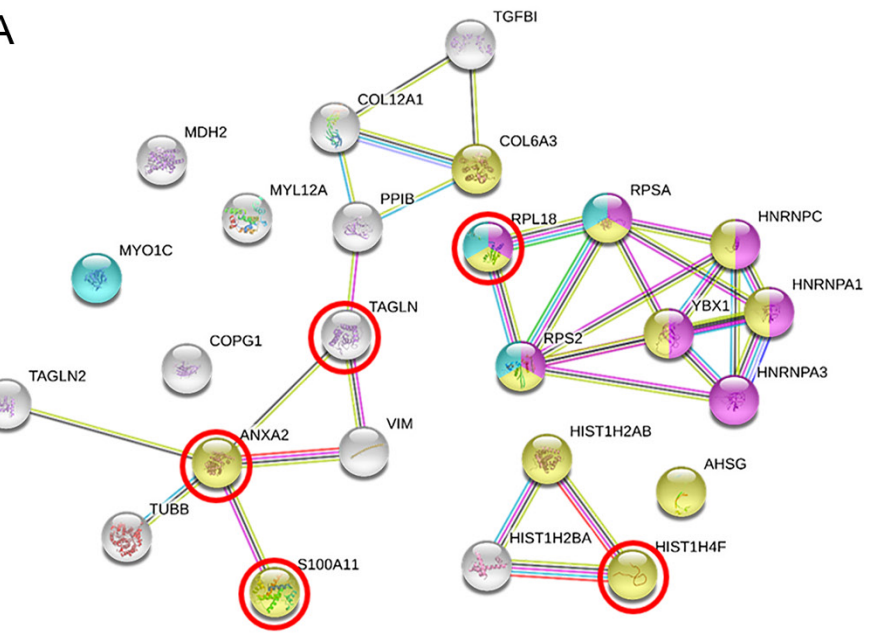

B

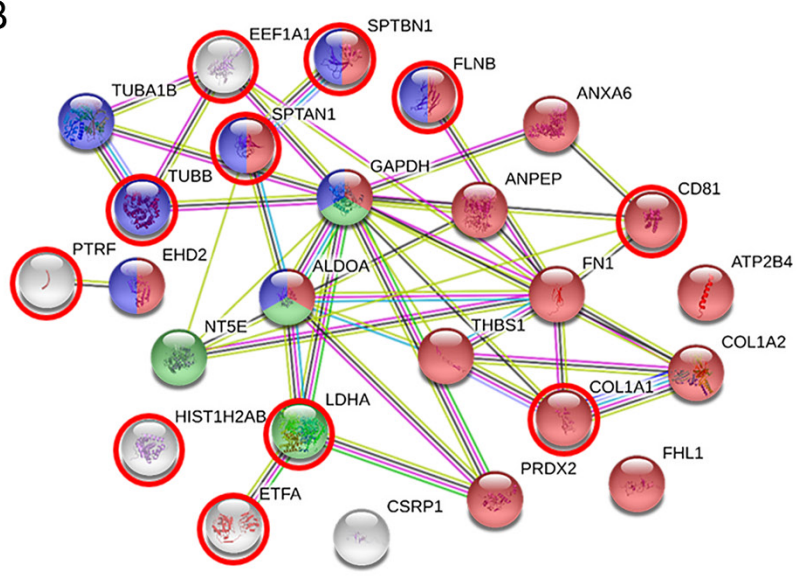

Figure 2. PPIs of the top 25 proteins differentially expressed in skin fibroblasts of patients with PD carrying (A) heterozygous acid- $\beta$ glucosidase variants and (B) heterozygous parkin variants. PPIs were mapped using STRING and categorized by biological processes based on Gene Ontology analysis. Yellow indicates proteins involved in negative regulation of macromolecular metabolic processes; purple indicates proteins involved in an mRNA metabolic process; cyan indicates proteins involved in targeting to the membrane; red indicates proteins involved in the regulation of biological quality; blue indicates proteins involved in cytoskeleton organization; and green indicates proteins involved in an NAD metabolic process. Red circles are proteins with differentially altered expression (>1.5-fold change) in the PD fibroblast group. Abbreviated protein names correspond to the full protein names shown in Table II. PPI, protein-protein interaction; PD, Parkinson's disease; STRING, using Search Tool for Retrieval of Interacting Genes. 
A

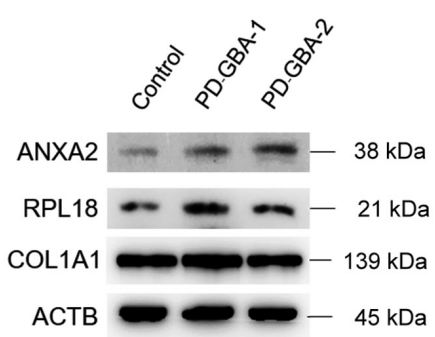

C

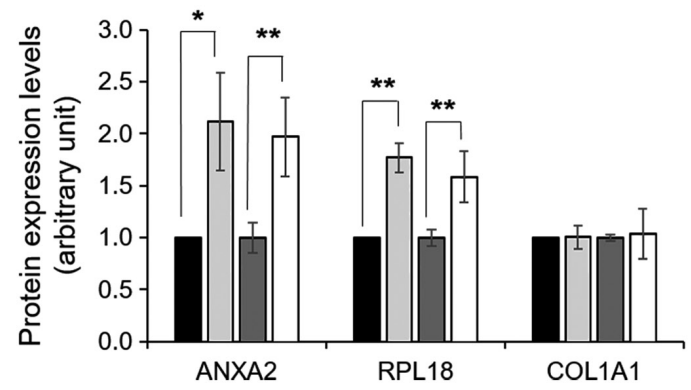

B

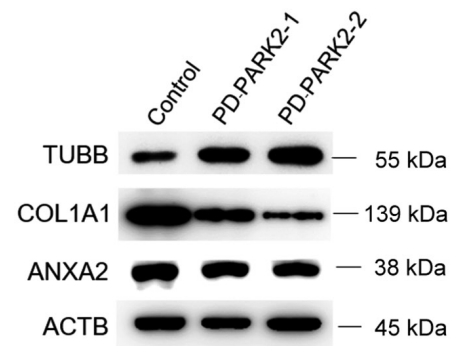

D

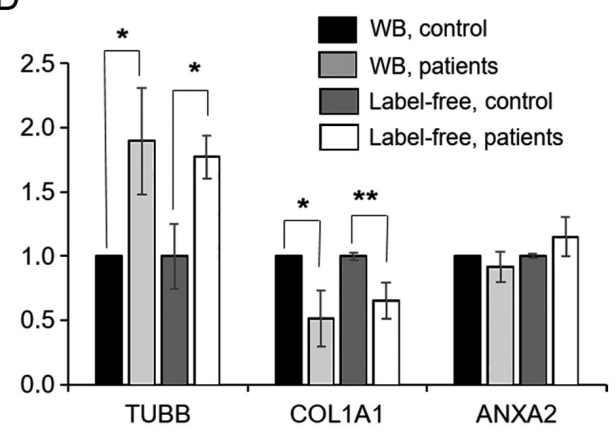

Figure 3. Validation of proteins expressed in pooled fibroblast samples of healthy controls, and in fibroblasts from patients with Parkinson's disease carrying GBA and PARK2 variants. (A) Representative western blots of ANXA2, RPL18 and COL1A1 in the GBA group. (B) Representative western blots of TUBB, COL1A1 and ANXA2 in the PARK2 group. ACTB was used for normalization of protein loading in each sample. (C and D) Relative ratios of protein expression levels obtained from western blot and label-free quantitative proteomic analyses. All protein levels were normalized to those of the pooled healthy control fibroblasts. Data are presented as the mean \pm standard deviation of at least two independent experiments. ${ }^{*} \mathrm{P}<0.05,{ }^{* *} \mathrm{P}<0.01$ vs. control. $\mathrm{PD}, \mathrm{Parkinson}$ 's disease; GBA, acid- $\beta$ glucosidase; PARK2, parkin; WB, western blot; label-free, label free quantitative proteomics.

proteins based on densitometry analysis were consistent with those obtained by the label-free quantitative proteomic analysis (Fig. 3C and D).

\section{Discussion}

Abnormalities in GBA and PARK2 genes have been reported previously to be strong risk factors for developing PD (28). In the present study, the GCase activity level was decreased in fibroblasts of patients with PD with $G B A$ variants [c.1309delG (pV398fsX404) and IVS2+1G>A] compared with that found in fibroblasts of healthy controls. In addition, the GCase activity from peripheral blood leucocytes of patients with PD carrying $G B A$ variants was lower than that observed in patients with PD without heterozygous $G B A$ variants and in healthy subjects (data not shown). Low GCase enzymatic activity has been previously reported in the cerebrospinal fluid of patients with PD and Lewy body dementia $(29,30)$, and in two brain autopsy studies $(31,32)$. The GCase activity in peripheral blood samples of $G B A-P D$ was reported to be lower than that of PD patients without $G B A$ variants from the Ashkenazi Jewish population (33). These findings are consistent with the observations of the present study.

In addition to $G B A$ variants, there is growing evidence to suggest that heterozygous pathogenic variants in the gene that encodes the parkin protein are also susceptibility factors for PD with a lower age of onset $(34,35)$. It was previously reported that heterozygosity for a single $P A R K 2$ variant in patients with deletions may contribute to PD (36). In the present study, two cases of heterozygous PARK2 variants were studied. The c.2T $>C$ (p.M1T) variant was previously described in a
Chinese patient (37). This variant showed a change in the start codon from ATG to ACG, resulting in the complete absence of the parkin protein. It was reported that $P A R K 2$ point variants are not exclusive to PD, and the presence of a single point variant in a patient in the absence of a second variant should not be considered a cause of disease unless it is corroborated by family data and functional studies (38). However, another report revealed that a large proportion of patients with a sporadic form of PD (21 of 327 patients with PD, 6.4\%) were carriers of heterozygous deletions or duplications in PARK2 (39). The authors suggested that these heterozygous forms may be considered dominant mutations with low penetrance (39). Therefore, further studies are required to identify the PD-associated effects of disease caused by heterozygous PARK2 variants.

Primary skin fibroblast cultures exhibit a patient-specific phenotype that recapitulates the PD chronological and epigenetic aging pattern, and are used as study models of several gene variants associated with PD $(17,20,40)$. Therefore, skin fibroblast cultures of patients with PD and healthy controls were used in the present study to explore proteins affected by these two variants. Based on quantitative proteomics and PPI analysis, the top 25 proteins with expression levels affected by $G B A$ variants belong to three categories, including negative regulation of macromolecule metabolic processes (12 proteins, GO:0010605), an mRNA metabolic process (7 proteins, GO:0016071) and protein targeting to the membrane (4 proteins, GO:0006612). ANXA2 was the most highly upregulated gene in the fibroblasts of patients with PD exhibiting $G B A$ variants. ANXA2 is involved in calcium signalling and is associated with S100A11 and TAGLN, which were also highly upregulated in the GBA fibroblasts of patients with PD. 
ANXA2 and S100A11 are $\mathrm{Ca}^{2+}$-dependent binding proteins, whereas TAGLN is an actin cross-linking protein involved in $\mathrm{Ca}^{2+}$ interactions and regulates contractile properties (41). It has been reported that several PD-associated proteins, including GBA, are associated with $\mathrm{Ca}^{2+}$ homeostasis (42). Kilpatrick et al (43) demonstrated that the GBA fibroblasts of patients with PD exhibited an increase in cytosolic $\mathrm{Ca}^{2+}$, whereas the lysosomal $\mathrm{Ca}^{2+}$ store content was reduced. The authors suggested that accelerated remodelling of $\mathrm{Ca}^{2+}$ stores by GBA may be involved in PD pathogenesis. ANXA2 is a multicompartmental protein that serves important roles in a range of intracellular membrane-related functions, including organization of specialized membrane microdomains, recruitment of peripheral membrane proteins, and regulation of membrane fusion and repair events (44). It has been reported that single nucleotide polymorphisms (SNPs) of ANXA2 were associated with an increased risk of stroke (45), and were a risk factor of avascular necrosis of the bone (osteonecrosis (46). ANXA2 is involved in numerous biological processes, including stress responses. It was reported that ANXA2 expression is increased after starvation, and this increase is associated with autophagy (47). ANXA2 is considered to be a brain pathology-associated protein, since its expression is increased under pathological conditions in various brain diseases $(48,49)$, but it was undetectable in the neurons and glial cells of a normal healthy brain (50). Furthermore, another study showed that skin fibroblasts of patients with PD exhibiting $G B A$ variants have altered GCase activity and impaired autophagic flux (40). S100A11 is implicated in membrane and cytoskeletal dynamics. It can interact with multiple cytoskeletal proteins, including tubulin, actin, ANXA1 and ANXA2 (51). Scherzer et al (52) reported that the S100A11 level was upregulated in peripheral blood samples of patients with PD. In addition, the S100A11 level was increased in amyotrophic lateral sclerosis, a neurodegenerative disease affecting motor neurons in the spinal cord and motor cortex (53). These data suggest that aberrant expression of ANXA2 and S100A11 may contribute to PD pathogenesis; however, further studies are required to clarify the mechanism(s) by which decreased GCase activity affects autophagic flux and the roles of $\mathrm{Ca}^{2+}$ in the function of ANXA2 and S100A11 in the cells of patients with PD.

It has been reported that numerous genes mutated in familial PD alter RNA metabolism, particularly mRNA translation, which may contribute to PD pathogenesis (54). Garcia-Esparcia et al (55) showed that the machinery of protein synthesis was altered, and several ribosomal protein (RP) subunits were abnormally regulated in the brain of patients with PD. The present study showed that the expression levels of several proteins involved in RNA metabolism, including RPL18, RPSA, RPS2, HNRNPC, HNRNPA1, HNRNPA3 and YBX1, were altered in the fibroblasts of patients with PD carrying $G B A$ variants. All these proteins are categorized in the group of mRNA metabolic process (GO:0016071). Among these, the level of RPL18 exhibited the greatest degree of upregulation in the GBA fibroblasts of patients with $\mathrm{PD}$, and it was involved in three $\mathrm{GO}$ processes. It is likely that $G B A$ variants may contribute to alterations of RNA metabolism; however, further studies are needed to investigate how GBA affects RNA metabolism.
Another major group of proteins affected by $G B A$ variants is the histone family. Based on PPI analysis, it was found that the levels of three histone family members, histones $\mathrm{H} 4$, $\mathrm{H} 2 \mathrm{~A}$ and $\mathrm{H} 2 \mathrm{~B}$, were strongly upregulated. It was reported that the expression levels of histone proteins and their acetylation were altered in PD brains (56). Therefore, it is necessary to clarify how $G B A$ variants modulate the expression of these histones.

PARK2 variants are involved in the alteration of proteins via three mechanisms, including regulation of biological quality (16 proteins, GO:0065008), cytoskeleton organization (8 proteins, GO:0019674) and NAD metabolic process (4 proteins, GO:0019674). The levels of TUBB showed the highest degree of upregulation in the PARK2 group. TUBB was directly linked to TUBA1B and GAPDH, which are involved in cytoskeleton organization (GO:0019674). It has been reported that the expression of several cytoskeletal proteins is altered in neurodegenerative diseases $(17,57,58)$. Microtubules, composed of $\alpha$ and $\beta$ forms, are essential components of neurons, and defects in tubulin genes are likely to cause neuronal diseases (59). It was reported that de novo mutations in TUBB5 (M299V, V353I and E401K) were found in microcephalic patients with structural brain abnormalities. These mutants were observed to affect the chaperone-dependent assembly of tubulin heterodimers, and to disrupt neurogenic division and/or migration in vivo (60). Generally, $\alpha$ and $\beta$-tubulins can polymerize as heterodimers that join to form microtubules. The correct folding of tubulin monomers and the formation of functional $\alpha / \beta$ heterodimers require a series of cellular chaperonins and co-factors (61). It was reported that parkin protein binds to $\alpha / \beta$ tubulin, and increases their ubiquitination as well as the degradation of misfolded tubulins in order to prevent cytotoxicity (62). Cartelli et al (57) showed an increased level of $\beta$-tubulin and actin in skin fibroblasts of patients with PD carrying PARK2 variants. These data are consistent with our results. Nevertheless, further investigation is required to determine why the $\beta$-tubulin found in skin fibroblasts of patients with PD carrying PARK2 variants is upregulated, and whether these increased levels are related to misfolding and malfunctions of ubiquitination.

Another major protein group affected by $P A R K 2$ variants is the group of proteins involved in the regulation of biological quality and extracellular matrix (ECM). The ECM is a network of extracellular macromolecules, including collagen, fibronectin (FN1) and thrombospondin-1 (THBS1), which regulate a range of cellular functions such as proliferation, migration and differentiation (63). It has been reported that alterations of several proteins in the ECM may be involved in the pathogenesis of neurodegenerative disorders (64). The present results showed that the levels of ECM proteins, including the collagen family members COL1A1 and COL1A2, FN1 and THBS1 were all downregulated in the patients with PD carrying PARK2 variants. The COL1A1 level was reported to be altered in fibroblasts of patients with PD (17). FN1 was shown to have a neuroprotective role in neuron-glial extrasynaptic transmission (65). THBS1 was reported to be a critical factor in the maintenance of adult neural progenitor cells (66). These data suggest that ECM proteins are involved in PD pathogenesis; however, further investigation is needed on how PARK2 variants affect ECM modelling. 
The present study has various limitations. Firstly, the proteins were identified without consideration of protein isoforms or processing, such as cleaved, mature and truncated forms or other post-translational modifications. Secondly, although the present study provides potential proteins associated with the disease, the numbers of patients with PD exhibiting $G B A$ and $P A R K 2$ variants from whom fibroblasts were acquired was small. Therefore, larger numbers of samples need to be analysed to represent phenotype and variant correlations. Lastly, the identified proteins obtained from skin fibroblasts of patients may not be the same as those of a patient's neuronal cells, which are more likely to demonstrate a direct clinical correlation with the variants. The results from studies focused on induced dopaminergic neurons derived from pluripotent stem cells from patients should reveal more precisely the molecular defects that occur in those neuronal cells $(67,68)$. Nevertheless, the present study on primary skin fibroblasts of patients with PD with different variants of $G B A$ and PARK2 genes provides unique proteome profiles, which suggest that the proteins identified may serve important roles in the disease status.

In conclusion, the present study used a label-free MS-based proteomic approach to study differentially expressed proteins in fibroblasts of patients with PD and healthy controls. Several proteins were identified, and a few predominant proteins were validated to confirm their expression levels. It was demonstrated that the proteome profiles of skin fibroblasts from patients with PD carrying heterozygous $G B A$ and $P A R K 2$ variants and those from healthy controls are different and unique. Heterozygous $G B A$ variants reveal a signature of protein alterations related to the regulation of macromolecular processes. Among these proteins, the ANXA2 level is most highly upregulated, and this increase is considered to be involved in autophagy regulation and $\mathrm{Ca}^{2+}$ homeostasis. Although heterozygous PARK2 variants are rare in patients with $\mathrm{PD}$, this heterozygous form shows a signature of protein alterations related to the regulation of cytoskeleton organization and biological quality. Among them, the TUBB level is most highly upregulated, and this increase is likely to be involved in cytoskeleton organization. However, further studies are required to clarify the functional roles of these proteins in the cells of patients with PD carrying $G B A$ and $P A R K 2$ variants. Taken together, this study demonstrated the value of the proteomic approach to identify proteome profiles and to compare their expression levels that may be associated with the physiological changes occurring in the cells. These alterations may be related to disease progression and development.

\section{Acknowledgements}

We would like to thank Dr Somsak Tanrattanakorn, Department of Medicine, Faculty of Medicine, Ramathibodi Hospital, Mahidol University, for his help with the skin biopsy.

\section{Funding}

This study was supported by the Chulabhorn Research Institute (grant no. BC-2020-05) and the Faculty of Medicine, Ramathibodi Hospital, Mahidol University.

\section{Availability of data and materials}

The datasets used and/or analysed during the present study are available from the corresponding author on reasonable request.

\section{Authors' contributions}

LN and VC conceived and designed the study. LN, PS, DC and $\mathrm{KK}$ performed the experiments. KS performed the bioinformatics analysis and statistical analysis. CS analysed and interpreted the results, and reviewed the manuscript. PS, LN, and VC wrote and drafted the manuscript. JS, JRKC, PD, and $\mathrm{TP}$ reviewed and edited the manuscript and were involved in the conception of the study. All authors read and approved the final manuscript. PS, LN and VC confirmed the authenticity of all the raw data.

\section{Ethics approval and consent to participate}

This study was approved by the Ethical Clearance Committee on Human Rights Related to Research Involving Human Subjects, Faculty of Medicine, Ramathibodi Hospital, Mahidol University (approval no. ID03-54-22).

\section{Patient consent for publication}

Not applicable.

\section{Competing interests}

The authors declare that they have no competing interests.

\section{References}

1. Kalia LV and Lang AE: Parkinson's disease. Lancet 386: 896-912, 2015.

2. Deng H, Wang $P$ and Jankovic J: The genetics of Parkinson disease. Ageing Res Rev 42: 72-85, 2018.

3. Hernandez DG, Reed X and Singleton AB: Genetics in Parkinson disease: Mendelian versus non-Mendelian inheritance. J Neurochem 139 (Suppl 1): 59-74, 2016.

4. Kuusimäki T, Korpela J, Pekkonen E, Martikainen MH, Antonini A and Kaasinen V: Deep brain stimulation for monogenic Parkinson's disease: A systematic review. J Neurol 267: 883-897, 2020.

5. Billingsley KJ, Bandres-Ciga S, Saez-Atienzar S and Singleton AB: Genetic risk factors in Parkinson's disease. Cell Tissue Res 373: 9-20, 2018.

6. Kitada T, Asakawa S, Hattori N, Matsumine H, Yamamura Y, Minoshima S, Yokochi M, Mizuno Y and Shimizu N: Mutations in the parkin gene cause autosomal recessive juvenile parkinsonism. Nature 392: 605-608, 1998.

7. Hattori N and Mizuno Y: Twenty years since the discovery of the parkin gene. J Neural Transm (Vienna) 124: 1037-1054, 2017.

8. Horowitz M, Wilder S, Horowitz Z, Reiner O, Gelbart T and Beutler E: The human glucocerebrosidase gene and pseudogene: Structure and evolution. Genomics 4: 87-96, 1989.

9. Hruska KS, LaMarca ME, Scott CR and Sidransky E: Gaucher disease: Mutation and polymorphism spectrum in the glucocerebrosidase gene (GBA). Hum Mutat 29: 567-583, 2008.

10. Pulkes T, Choubtum L, Chitphuk S, Thakkinstian A, Pongpakdee S, Kulkantrakorn K, Hanchaiphiboolkul S, Tiamkao S and Boonkongchuen P: Glucocerebrosidase mutations in Thai patients with Parkinson's disease. Parkinsonism Relat Disord 20: 986-991, 2014

11. Lwin A, Orvisky E, Goker-Alpan O, LaMarca ME and Sidransky E: Glucocerebrosidase mutations in subjects with parkinsonism. Mol Genet Metab 81: 70-73, 2004. 
12. Aharon-Peretz J, Rosenbaum $\mathrm{H}$ and Gershoni-Baruch $\mathrm{R}$ : Mutations in the glucocerebrosidase gene and Parkinson's disease in Ashkenazi Jews. N Engl J Med 351: 1972-1977, 2004.

13. Sidransky E, Nalls MA, Aasly JO, Aharon-Peretz J, Annesi G, Barbosa ER, Bar-Shira A, Berg D, Bras J, Brice A, et al: Multicenter analysis of glucocerebrosidase mutations in Parkinson's disease. N Engl J Med 361: 1651-1661, 2009.

14. Malek N, Weil RS, Bresner C, Lawton MA, Grosset KA, Tan M, Bajaj N, Barker RA, Burn DJ, Foltynie T, et al; PRoBaND clinical consortium: Features of GBA-associated Parkinson's disease at presentation in the UK Tracking Parkinson's study. J Neurol Neurosurg Psychiatry 89: 702-709, 2018.

15. Ziegler SG, Eblan MJ, Gutti U, Hruska KS, Stubblefield BK, Goker-Alpan O,LaMarca ME and SidranskyE: Glucocerebrosidase mutations in Chinese subjects from Taiwan with sporadic Parkinson disease. Mol Genet Metab 91: 195-200, 2007.

16. Schapira AH: Glucocerebrosidase and Parkinson disease: Recent advances. Mol Cell Neurosci 66 (Pt A): 37-42, 2015

17. Lippolis R, Siciliano RA, Pacelli C, Ferretta A, Mazzeo MF, Scacco S, Papa F, Gaballo A, Dell'Aquila C, De Mari M, et al: Altered protein expression pattern in skin fibroblasts from parkin-mutant early-onset Parkinson's disease patients. Biochim Biophys Acta 1852: 1960-1970, 2015.

18. Rotunno MS, Lane M, Zhang W, Wolf P, Oliva P, Viel C, Wills AM, Alcalay RN, Scherzer CR, Shihabuddin LS, et al: Cerebrospinal fluid proteomics implicates the granin family in Parkinson's disease. Sci Rep 10: 2479, 2020.

19. O'Bryant SE, Edwards M, Zhang F, Johnson LA, Hall J, Kuras Y and Scherzer CR: Potential two-step proteomic signature for Parkinson's disease: Pilot analysis in the Harvard Biomarkers Study. Alzheimers Dement (Amst) 11: 374-382, 2019.

20. Auburger G, Klinkenberg M,Drost J,Marcus K, Morales-Gordo B, Kunz WS, Brandt U, Broccoli V, Reichmann H, Gispert S, et al: Primary skin fibroblasts as a model of Parkinson's disease. Mol Neurobiol 46: 20-27, 2012.

21. KhwanrajK, ChoubtumL, Taweewongsounton A,Tanrattanakorn S, Pulkes T and Dharmasaroja P: Mitochondrial Respiratory Chain Enzymatic Activities on Skin Fibroblasts in Patients With Mutan Glucocerebrosidase and PARK2 Genes. J Neurol Res 6: 12-17, 2016.

22. Peters SP, Coyle P and Glew RH: Differentiation of beta-glucocerebrosidase from beta-glucosidase in human tissues using sodium taurocholate. Arch Biochem Biophys 175: 569-582, 1976.

23. Chokchaichamnankit D, Watcharatanyatip K, Subhasitanont $P$, Weeraphan C, Keeratichamroen S, Sritana N, Kantathavorn N, Diskul-Na-Ayudthaya P, Saharat K, Chantaraamporn J, et al: Urinary biomarkers for the diagnosis of cervical cancer by quantitative label-free mass spectrometry analysis. Oncol Lett 17: 5453-5468, 2019.

24. Team RC: A language and environment for statistical computing. R Foundation for Statistical Computing, Vienna, Austria. www.r-project.org.

25. Szklarczyk D, Gable AL, Lyon D, Junge A, Wyder S, Huerta-Cepas J, Simonovic M, Doncheva NT, Morris JH, Bork P, et al: STRING v11: Protein-protein association networks with increased coverage, supporting functional discovery in genome-wide experimental datasets. Nucleic Acids Res 47D: D607-D613, 2019.

26. Ashburner M, Ball CA, Blake JA, Botstein D, Butler H, Cherry JM, Davis AP, Dolinski K, Dwight SS, Eppig JT, et al; The Gene Ontology Consortium: Gene ontology: Tool for the unification of biology. Nat Genet 25: 25-29, 2000.

27. The Gene Ontology Consortium: The Gene Ontology Resource: 20 years and still GOing strong. Nucleic Acids Res 47D: D330-D338, 2019

28. Delamarre A and Meissner WG: Epidemiology, environmental risk factors and genetics of Parkinson's disease. Presse Med 46 175-181, 2017.

29. Balducci C, Pierguidi L, Persichetti E, Parnetti L, Sbaragli M, Tassi C, Orlacchio A, Calabresi P, Beccari T and Rossi A: Lysosomal hydrolases in cerebrospinal fluid from subjects with Parkinson's disease. Mov Disord 22: 1481-1484, 2007.

30. Borroni B, Gardoni F, Parnetti L, Magno L, Malinverno M, Saggese E, Calabresi P, Spillantini MG, Padovani A and Di Luca M: Pattern of Tau forms in CSF is altered in progressive supranuclear palsy. Neurobiol Aging 30: 34-40, 2009.

31. Gegg ME, Burke D, Heales SJ, Cooper JM, Hardy J, Wood NW and Schapira AH: Glucocerebrosidase deficiency in substantia nigra of parkinson disease brains. Ann Neurol 72: 455-463, 2012 .
32. Murphy KE, Gysbers AM, Abbott SK, Tayebi N, Kim WS Sidransky E, Cooper A, Garner B and Halliday GM: Reduced glucocerebrosidase is associated with increased $\alpha$-synuclein in sporadic Parkinson's disease. Brain 137: 834-848, 2014.

33. Ortega RA, Torres PA, Swan M, Nichols W, Boschung S, Raymond D, Barrett MJ, Johannes BA, Severt L, Shanker V, et al: Glucocerebrosidase enzyme activity in GBA mutation Parkinson's disease. J Clin Neurosci 28: 185-186, 2016.

34. Sun M, Latourelle JC, Wooten GF, Lew MF, Klein C, Shill HA, Golbe LI, Mark MH, Racette BA, Perlmutter JS, et al: Influence of heterozygosity for parkin mutation on onset age in familial Parkinson disease: The GenePD study. Arch Neurol 63: 826-832, 2006.

35. Klein C, Lohmann-Hedrich K, Rogaeva E, Schlossmacher MG and Lang AE: Deciphering the role of heterozygous mutations in genes associated with parkinsonism. Lancet Neurol 6: 652-662, 2007.

36. Wu YR, Wu CH, Chao CY, Kuan CC, Zhang WL, Wang CK, Chang CY, Chang YC, Lee-Chen GJ and Chen CM: Genetic analysis of Parkin in early onset Parkinson's disease (PD): Novel intron $9 \mathrm{~g}>$ a single nucleotide polymorphism and risk of Taiwanese PD. Am J Med Genet B Neuropsychiatr Genet 153B: 229-234, 2010.

37. Zhang BR, Hu ZX, Yin XZ, Cai M, Zhao GH, Liu ZR and Luo W: Mutation analysis of parkin and PINK1 genes in early-onset Parkinson's disease in China. Neurosci Lett 477: 19-22, 2010.

38. Kay DM, Moran D, Moses L, Poorkaj P, Zabetian CP, Nutt J, Factor SA, Yu CE, Montimurro JS, Keefe RG, et al: Heterozygous parkin point mutations are as common in control subjects as in Parkinson's patients. Ann Neurol 61: 47-54, 2007.

39. Shulskaya MV, Shadrina MI, Fedotova EY, Abramycheva NY, Limborska SA, Illarioshkin SN and Slominsky PA: Second mutation in PARK2 is absent in patients with sporadic Parkinson's disease and heterozygous exonic deletions/duplications in parkin gene. Int J Neurosci 127: 781-784, 2017.

40. Collins LM, Williams-Gray CH, Morris E, Deegan P, Cox TM and Barker RA: The motor and cognitive features of Parkinson's disease in patients with concurrent Gaucher disease over 2 years: A case series. J Neurol 265: 1789-1794, 2018.

41. Assinder SJ, Stanton JA and Prasad PD: Transgelin: An actin-binding protein and tumour suppressor. Int J Biochem Cell Biol 41: 482-486, 2009.

42. Zaichick SV, McGrath KM and Caraveo G: The role of $\mathrm{Ca}^{2+}$ signaling in Parkinson's disease. Dis Model Mech 10: 519-535, 2017.

43. Kilpatrick BS, Magalhaes J, Beavan MS, McNeill A, Gegg ME, Cleeter MW, Bloor-Young D, Churchill GC, Duchen MR, Schapira $\mathrm{AH}$, et al: Endoplasmic reticulum and lysosomal $\mathrm{Ca}^{2+}$ stores are remodelled in GBA1-linked Parkinson disease patient fibroblasts. Cell Calcium 59: 12-20, 2016.

44. Gerke V, Creutz CE and Moss SE: Annexins: Linking $\mathrm{Ca}^{2+}$ signalling to membrane dynamics. Nat Rev Mol Cell Biol 6: 449-461, 2005

45. Sebastiani P, Ramoni MF, Nolan V, Baldwin CT and Steinberg MH: Genetic dissection and prognostic modeling of overt stroke in sickle cell anemia. Nat Genet 37: 435-440, 2005.

46. Baldwin C, Nolan VG, Wyszynski DF, Ma QL, Sebastiani P, Embury SH, Bisbee A, Farrell J, Farrer L and Steinberg MH: Association of klotho, bone morphogenic protein 6 , and annexin A2 polymorphisms with sickle cell osteonecrosis. Blood 106: 372-375, 2005.

47. Moreau K, Ghislat G, Hochfeld W, Renna M, Zavodszky E, Runwal G, Puri C, Lee S, Siddiqi F, Menzies FM, et al: Transcriptional regulation of Annexin A2 promotes starvation-induced autophagy. Nat Commun 6: 8045, 2015.

48. Nygaard SJ, Haugland HK, Kristoffersen EK, Lund-Johansen M, Laerum OD and Tysnes OB: Expression of annexin II in glioma cell lines and in brain tumor biopsies. J Neurooncol 38: 11-18, 1998.

49. Eberhard DA, Brown MD and VandenBerg SR: Alterations of annexin expression in pathological neuronal and glial reactions. Immunohistochemical localization of annexins I, II (p36 and p11 subunits), IV, and VI in the human hippocampus. Am J Pathol 145: 640-649, 1994.

50. de la Monte SM, Bhavani K, Xu YY, Puisieux A and Wands JR: Modulation of p36 gene expression in human neuronal cells. J Neurol Sci 128: 122-133, 1995.

51. Réty S, Osterloh D, Arié JP, Tabaries S, Seeman J, Russo-Marie F, Gerke V and Lewit-Bentley A: Structural basis of the $\mathrm{Ca}(2+)$-dependent association between S100C (S100A11) and its target, the N-terminal part of annexin I. Structure 8: 175-184, 2000. 
52. Scherzer CR, Gullans SR and Jensen R: Prediction of Parkinson's disease using gene expression levels of peripheral blood samples. US Patent 7595159B2 2009. Filed: November 3,2005; issued: September 29, 2009.

53. Iridoy MO, Zubiri I, Zelaya MV, Martinez L, Ausín K, Lachen-Montes M, Santamaría E, Fernandez-Irigoyen J and Jericó I: Neuroanatomical Quantitative Proteomics Reveals Common Pathogenic Biological Routes between Amyotrophic Lateral Sclerosis (ALS) and Frontotemporal Dementia (FTD). Int J Mol Sci 20: 20, 2018.

54. Lu B, Gehrke S and Wu Z: RNA metabolism in the pathogenesis of Parkinson's disease. Brain Res 1584: 105-115, 2014.

55. Garcia-Esparcia P, Hernández-Ortega K, Koneti A, Gil L, Delgado-Morales R, Castaño E, Carmona M and Ferrer I: Altered machinery of protein synthesis is region- and stage-dependent and is associated with $\alpha$-synuclein oligomers in Parkinson's disease. Acta Neuropathol Commun 3: 76, 2015.

56. Toker L, Tran GT, Sundaresan J, Tysnes O-B, Alves G, Haugarvoll K, Nido GS, Dolle C and Tzoulis C: Genome-wide dysregulation of histone acetylation in the Parkinson's disease brain. BioR xiv: Apr 2, 2020 (Epub ahead of print). doi: https://doi. org/10.1101/785550.

57. Cartelli D, Goldwurm S, Casagrande F, Pezzoli G and Cappelletti G: Microtubule destabilization is shared by genetic and idiopathic Parkinson's disease patient fibroblasts. PLoS One 7: e37467, 2012.

58. Cairns NJ, Lee VM and Trojanowski JQ: The cytoskeleton in neurodegenerative diseases. J Pathol 204: 438-449, 2004

59. Tischfield MA, Baris HN, Wu C, Rudolph G, Van Maldergem L, He W, Chan WM, Andrews C, Demer JL, Robertson RL, et al: Human TUBB3 mutations perturb microtubule dynamics, kinesin interactions, and axon guidance. Cell 140: 74-87, 2010.

60. Breuss M, Heng JI, Poirier K, Tian G, Jaglin XH, Qu Z, Braun A, Gstrein T, Ngo L, Haas M, et al: Mutations in the $\beta$-tubulin gene TUBB5 cause microcephaly with structural brain abnormalities. Cell Rep 2: 1554-1562, 2012.
61. Lewis SA, Tian G and Cowan NJ: The alpha- and beta-tubulin folding pathways. Trends Cell Biol 7: 479-484, 1997.

62. Ren Y, Zhao J and Feng J: Parkin binds to alpha/beta tubulin and increases their ubiquitination and degradation. J Neurosci 23: 3316-3324, 2003.

63. Bonnans C, Chou J and Werb Z: Remodelling the extracellular matrix in development and disease. Nat Rev Mol Cell Biol 15: 786-801, 2014.

64. Bielefeld KA, Amini-Nik S, Whetstone H, Poon R, Youn A, Wang J and Alman BA: Fibronectin and beta-catenin act in a regulatory loop in dermal fibroblasts to modulate cutaneous healing. J Biol Chem 286: 27687-27697, 2011.

65. Wang J, Yin L and Chen Z: Neuroprotective role of fibronectin in neuron-glial extrasynaptic transmission. Neural Regen Res 8: 376-382, 2013

66. Lu Z and Kipnis J: Thrombospondin 1 - a key astrocyte-derived neurogenic factor. FASEB J 24: 1925-1934, 2010.

67. Shuvalova LD, Eremeev AV, Bogomazova AN, Novosadova EV, Zerkalenkova EA, Olshanskaya YV, Fedotova EY, Glagoleva ES, Illarioshkin SN, Lebedeva OS, et al: Generation of induced pluripotent stem cell line RCPCMi004-A derived from patient with Parkinson's disease with deletion of the exon 2 in PARK2 gene. Stem Cell Res (Amst) 44: 101733, 2020.

68. Gustavsson N, Marote A, Pomeshchik Y, Russ K, Azevedo C, Chumarina M, Goldwurm S, Collin A, Pinto L, Salgado AJ, et al: Generation of an induced pluripotent stem cell line (CSC-46) from a patient with Parkinson's disease carrying a novel p.R301C mutation in the GBA gene. Stem Cell Res (Amst) 34: 101373, 2019.

This work is licensed under a Creative Commons Attribution-NonCommercial-NoDerivatives 4.0 International (CC BY-NC-ND 4.0) License. 